\title{
Os Impactos Processuais da Inobservância Procedimental no Âmbito da Cadeia de Custódia
}

\author{
The Procedural Impacts of the Procedural Inobservance Within the Custody Chain
}

\author{
Almir Santos Reis Junior ${ }^{\text {abcc }}$, Larissa Crislaine França ${ }^{a}$ \\ ${ }^{a}$ Universidade Estadual de Maringá, Curso de Direito. PR, Brasil. \\ bUniversidade Católica de Moçambique, Programa de Pós-Graduação Stricto Sensu em Direito Público. Moçambique. \\ 'Universidade de Santiago, Programa de Pós-Graduação Stricto Sensu em Direito. Cabo Verde. \\ E-mail:
}

\begin{abstract}
Resumo
A cadeia de custódia foi introduzida na legislação processual por meio da Lei 13.964/19, com escopo de garantir o registro e o rastreamento da prova pericial, desde seu nascimento até o seu perecimento, para garantir a integridade dos vestígios de determinado crime. Sob esta lente, o presente trabalho analisa as consequências jurídicas sobre a quebra da cadeia de custódia, no intuito de averiguar se tal quebra causaria a inadmissibilidade da prova ou diminuiria o seu valor probatório. Para tanto, empregou-se o método hipotético-dedutivo que consistiu na revisão bibliográfica de doutrina nacional e estrangeira. Chegou-se a conclusão de que a ruptura da cadeia de custódia culmina na produção de provas ilegítimas no processo penal, devendo ser desentranhadas dos autos e inutilizadas.
\end{abstract}

Palavras-chave: Ilicitude da Prova. Inadmissibilidade das Provas Ilícitas. Lei Anticrime. Quebra da Cadeia de Custódia.

\begin{abstract}
The chain of custody was introduced in the procedural legislation through the Law 13.964/19, with the aim to assure the registration and to track the expert evidence, from its birth to its perishing, to guarantee the integrity of the traces of a certain crime. Under this lens, the present study analyzes the legal consequences of the break on the chain of custody, in order to ascertain whether such breach would cause the evidence to be inadmissible or if it would decrease its probative value. For this, the hypothetical-deductive method was applied, which consisted in a bibliographic review of national and foreign doctrine. The conclusion reached was that the rupture on the chain of custody culminates in the production of illegitimate evidence in the criminal proceedings, which must be removed from the records and discarded.
\end{abstract}

Keywords: Illicit Evidence. Suppression Doctrine. Anticrime Law. Break on the Chain of Custody.

\section{Introdução}

A legislação processual penal brasileira deve ser interpretada à luz da Constituição Federal, de 1988, a qual consagra, dentre outros, os princípios do contraditório, da ampla defesa, da imparcialidade do juiz e do devido processo legal, confirmando, assim, a adoção do sistema acusatório pelo ordenamento pátrio, o qual repugna as provas obtidas por meios ilícitos.

Nesse sentido, o presente trabalho aborda o instituto da cadeia de custódia, mecanismo introduzido na legislação processual penal brasileira, por meio da Lei $n^{0}$ 13.964/2019, que incluiu, no Código de Processo Penal, os arts. 158-A ao 158-F. A atenção especial concentrar-se-á na verifica $\bigotimes \bigotimes \mathbf{0}$ das consequências jurídicas (validade ou invalidade) acerca da violação das normativas referentes à cadeia de custódia da prova, ante o silêncio do legislador quanto ao tema.

Tal discussão é dotada de atualidade uma vez que a cadeia de custódia, no processo penal, consiste em um dos institutos incumbidos de amparar muitas decisões judiciais, especialmente, em crimes que deixam vestígios. A discussão permitirá o debate com escopo de identificar regras que garantam a integralidade e confiabilidade do laudo pericial, alicerces para o julgador formar seu convencimento.

\section{Desenvolvimento}

\subsection{Metodologia}

A pesquisa foi desenvolvida por meio do emprego do método hipotético-dedutivo que consistiu na revisão bibliográfica de doutrinas relevantes que indicam a verdadeira fonte indireta do direito, produzida por enunciados lógicos conexos à Ciência do Direito, sem prejuízo da análise da legislação e da jurisprudência que tratam da temática, com escopo de responder a problemática ligada às consequências jurídicas nos casos de quebramento da cadeia de custódia.

\subsection{Da Cadeia de Custódia e seus Impactos no Processo Penal}

Provar o acontecimento de um ato criminoso consiste um dos aspectos centrais em uma investigação criminal. Tornouse proeminente a necessidade de avaliação do trabalho pericial junto à instituição da cadeia de custódia das provas, com intuito de garantir e conservar as evidências deixadas 
pela infração penal.

No Estado Democrático de Direito os fins não justificam os meios, com o intuito de legitimar a busca da verdade mediante o uso de qualquer fonte probatória. A investigação e a instrução criminal desenvolvem-se nos limites e segundo os critérios legais, pois "a investigação criminal e a luta contra a criminalidade devem ser conduzidas de acordo com um rito probatório legalmente predeterminado" (GRINOVER, 1982, p. 58).

A introdução do instituto da cadeia de provas, por meio da Lei 13.964/19,

reflete o reconhecimento de que a fiabilidade constitui uma importante característica dos elementos que comporão o conjunto probatório a ser valorado pelo juiz para determinação dos fatos juridicamente relevantes (MATIDA, 2020, p.2).

Para Matida (2020), o papel da cadeia de custódia da prova, a qual pode ser, grosso modo, conceituada como documentação cronológica do vestígio (aqui entendido em um sentido amplo), é exatamente o de assegurar que o elemento probatório que o árbitro judicial recebe na fase de instrução seja dotado de confiabilidade; foi colhido, catalogado, manipulado, condicionado e transportado devidamente até ser incorporado à persecução penal.

Embora atualmente prevista nos arts. 158-A ao 158-F, do Código de Processo Penal, vale registrar que antes de sua introdução no Código de Processo Penal, tal instituto já existia no Brasil, desde o ano de 2014, quando houve sua criação e regulação por meio da Portaria $n^{\circ} 84$, da Secretaria Nacional de Segurança Pública do Ministério da Justiça. Então, o advento e sua introdução, no Código de Processo Penal, apenas positivou o instituto já existente desde o ano de 2014.

A cadeia de custódia, por meio do rastreamento, armazenamento e registro de todas as ações da prova pericial, garante tanto a lisura e a idoneidade tanto do material coletado quanto da perícia que dele nasce. Seus elementos, por existirem independente e extraprocessualmente, deverão ser coletados e levados ao processo por algum meio documental, ou seja, por intermédio de laudo pericial.

Sempre que a atividade probatória envolver a coleta, o armazenamento ou a análise de fontes de provas reais, será primordial a adoção de determinados cuidados, a fim de assegurar a autenticidade, a integridade e a garantia de que o objeto (evidência) levado ao processo para ser valorado, pelo juiz, seja justamente aquele encontrado, apreendido e periciado. É por essa razão que a cadeia custódia representa tanta importância ao processo penal.

Pode-se afirmar, então, que a cadeia de custódia consiste em um procedimento de documentação ininterrupta da prova pericial, cujas fases são (LIMA, 2020):

a) Reconhecimento de elementos (vestígios) que podem ser objeto de perícia. Ex. arma, sangue, digitais, cadáver, celular;

b) Isolamento: consiste na preservação do ambiente em sua íntegra, deixando-o imaculado; c) Fixação: consiste na descrição detalhada do vestígio conforme se encontra no local de crime ou no corpo de delito, e a sua posição na área de exames, podendo ser ilustrada por fotografias, filmagens ou croqui, sendo indispensável a sua descrição no laudo pericial produzido pelo perito responsável pelo atendimento;

d) Coleta: ato de recolher o vestígio para exame. Em regra, a coleta deve ser feita preferencialmente por perito (158C);

e) Acondicionamento: ato de colocar o vestígio em embalagem própria para ser levado ao órgão; com anotação da data, hora e nome de quem realizou a coleta e o acondicionamento;

f) Transporte: transferência do material até o órgão responsável (IML; IC);

g) Recebimento: ato de transferência do vestígio ao órgão/ perito responsável pela análise, com informações referentes ao número de procedimento e unidade de polícia judiciária relacionada, local de origem, nome de quem transportou o vestígio, código de rastreamento, natureza do exame, tipo do vestígio, protocolo, assinatura e identificação de quem o recebeu;

h) Processamento: exame pericial, em si;

i) Armazenamento: procedimento referente à guarda, em condições adequadas, do material a ser processado, guardado para realização de contraperícia, descartado ou transportado, com vinculação ao número do laudo correspondente; e

j) Descarte: procedimento referente à liberação do vestígio.

Cada operação acima deve ser rigorosamente registrada em ordem cronológica para apoiar eventual contestação sobre sua legalidade e autenticidade, pelas partes. A documentação deve conter as circunstâncias sob as quais as evidências foram colhidas, a identidade dos manipuladores, a duração da custódia, a segurança de armazenagem do elemento probatório e como o vestígio foi transportado aos curadores sucessivos em cada elo da cadeia (BADARÓ, 2018).

Amesmidade da prova, na cadeia de custódia, visa assegurar que as evidências encontradas na fase de investigação, por aquele que estava procurando elementos a fim de determinar a ocorrência dos fatos que são relevantes, sejam as mesmas que serão apresentadas em juízo. Em outras palavras, significa dizer que a mesmidade busca evitar qualquer perda de identidade entre o elemento que foi encontrado e apreendido para ser periciado e o laudo correspondente apresentado ao juiz, com objetivo de não ocorrer perda de confiança na prova produzida (PRADO, 2014a). Para tanto, é fundamental respeitar um conjunto de garantias formais da custódia e tratamento do elemento de prova, a fim de evitar qualquer mudança ou alteração da evidência.

É nesse sentido, que advoga Prado (2014a, p.3), ao expor que:

a cadeia de custódia fundamenta-se no princípio universal de 'autenticidade da prova', definido como 'lei da mesmidade', isto é, o princípio pelo qual se determina que o mesmo que se encontrou na cena [do crime] é o mesmo que se está utilizando para tomar a decisão judicial'. Compreende-se, pois, que a formação e preservação do elemento probatório sejam cercadas de cuidados, independentemente da previsão expressa de regras processuais penais no direito ordinário. 
Além disso, a matéria está intimamente ligada ao princípio da desconfiança, pelo qual a parte contrária, na relação processual, questiona a legitimidade da evidência. Portanto, é fundamental, na ocorrência de infrações não-transeuntes, ou seja, aquelas que deixam vestígios, que os operadores da evidência sigam as diretrizes da cadeia de custódia, pois somente dessa forma ter-se-á a idoneidade do laudo pericial.

Em síntese, o comprometimento da mesmidade e o acometimento da desconfiança, colocam em risco, em alguma medida, a confiabilidade do elemento probatório; causas que podem ser afastadas por meio da rigorosa observância da cadeia de custódia, na medida em que suas diretrizes obstam a manipulação indevida do conjunto de provas, com a intenção de propiciar melhor arrimo probatório, com impactos positivos na efetividade dos princípios do contraditório e da ampla defesa (PRADO, 2014a).

\subsection{Das Adversidades da Prova Pericial}

Quando se discute sobre os elementos probatórios que concentram maior grau de credibilidade, como por exemplo o DNA ou as interceptações telefônicas, o debate cerca da violação da cadeia de custódia é ainda mais relevante e grave, tendo em vista que muitas decisões se apoiam, quase que exclusivamente, nestes meios de provas para reconhecer a materialidade e/ou autoria delitiva.

A discussão acerca da temática é bastante delicada quando se leva em consideração que a perícia criminal brasileira carece de estrutura física e segurança para sua organização, padronização de procedimentos e suficiência tecnológica. Soma-se a isso o fato de que os órgãos periciais estão comprometidos, por motivos históricos e administrativos, com a cultura policial. Este comprometimento faz prevalecer a investigação de natureza inquisitorial, na qual há uma eleição preliminar de um culpado antes mesmo da apreciação dos indícios materiais, em detrimento da investigação compromissada com os métodos científicos (GIOVANELLI; GARRIDO, 2011).

No Paraná, por exemplo, há apenas 11 unidades do Instituto de Criminalística (Curitiba, Cascavel, Foz do Iguaçu, Francisco Beltrão, Guarapuava, Londrina, Maringá, Paranaguá, Pato Branco, Ponta Grossa e Umuarama), responsáveis por atender 399 municípios, ainda contando com poucos servidores. Em outras palavras, há escassez de unidades e pessoal técnico para desenvolvimento das atividades periciais, cuja as atribuições são elevadas, pois envolve várias áreas do conhecimento humano, tais como: cibernética, DNA forense, engenharia legal, engenharia ambiental, laboratorial, localística, fonoaudiológica, documentoscópica, dentre outras.

Somado a tal fato, no que concerne às provas periciais, Lopes Junior (2020, p.675) alerta para a necessidade de se afastar do endeusamento da ciência como verdade absoluta, pois também está sujeita a erros que impactam em muitas decisões judiciais. Para ele "o progresso da ciência não garante uma pesquisa imune a erros e seus métodos, aceitos pela generalidade dos estudiosos em um determinado momento, podem parecer errôneos no momento seguinte" (LOPES JUNIOR, 2020, p.675).

Para tanto, é importante recordar-se que, na exposição de motivos do Código de Processo Penal, tem-se que: "todas as provas são relativas; nenhuma delas terá, ex vi legis, valor decisivo, ou necessariamente maior prestígio que outras". Esta exposição assume papel importante no sistema de persuasão racional do julgador, no qual não há hierarquia entre os meios de provas, podendo o juiz apoiar-se em qualquer prova para formar seu convencimento, desde que o fundamente.

Além disso, o relatório elaborado pela Secretaria Nacional de Segurança Pública - SANESP, publicado no ano de 2013, aponta que a perícia brasileira é precária de padronização estrutural, estruturando-se de maneira diversa em cada Estado e no Distrito Federal. Somado ao fato do desconhecimento da organização institucional por seus próprios gestores; o desenvolvimento da perícia ainda encontra como dificuldade a sistematização de dados. O relatório também explicitou a carência de profissionais habilitados e equipamentos (BRASIL, 2013).

Em que pese o fato de alguns poucos peritos poderem incorporar nos circuitos científicos por meio de associação com universidades, a maior parte das instituições periciais existentes no Brasil não estão em conformidade com os saberes e práticas fundamentais adotados na comunidade científica internacional vigente (GIOVANELLI; GARRIDO, 2011).

Assim, em razão da complexidade das provas periciais, é fundamental o investimento público para que seja devidamente aplicada e mantida a cadeia de custódia, considerando a necessidade de se assegurar que o elemento probatório possua as mesmas propriedades de quando foi colhido pelo perito oficial.

\subsection{A Quebra da Cadeia de Custódia e as Implicações Processuais}

Apesar da recente inserção do instituto da cadeia de custódia na legislação processual penal brasileira, Borri e Soares (2020) alertam sobre a ausência de normativa que disponha sobre as consequências quanto ao descumprimento dos dispositivos legais que regulamentam a matéria, ou seja, sobre a quebra da cadeia de custódia. Para os autores,

o que se pode notar a partir da introdução do instituto no ordenamento jurídico é que o desrespeito às etapas definidas pela lei quanto à cronologia do vestígio coletado, que vai desde o nascedouro até a valoração pelo magistrado, levará invariavelmente à constatação de inobservância das imposições legais, sem que se possa, todavia, afirmar com segurança quais seriam as obrigações do juiz no momento de se trabalhar com a prova (BORRI; SOARES, 2020, p.56).

Realmente, não há previsão normativa expressa que imponha sanção a eventuais violações à quebra da cadeia de custódia. Contudo, no que se refere a esta discussão, existem duas posições doutrinárias. A primeira, adotada 
por Prado (2014a), Eberhardt (2015), Lopes Junior e Rosa (2015), defende que a quebra da cadeia de custódia torna a prova ilegal, acarretando sua inadmissibilidade no processo. A segunda posição, adotada por Dallagnol e Câmara (2016) e Badaró (2018), considera que a de falta ou diminuição de confiabilidade da prova não dificultaria a sua inserção no processo, devendo ser este fato avaliado, pelo juiz, no momento da valoração da prova.

Como apontam Borri e Soares (2020), o debate está fundado no real alcance da violação da cadeia de custódia, seja pela consideração de ilicitude da prova, com o seu inevitável desentranhamento do processo; seja pela compreensão de que há uma nulidade, devendo esta ser valorada, com a possibilidade de renovação do ato ou de atribuição de menor valor probatório a ele com sua continuidade no processo.

Para Prado (2014b), há um risco na ausência de previsão normativa quanto às consequências do descumprimento dos preceitos relativos à cadeia de custódia. Entretanto, a ausência de previsão legal, deverá ser suprida, pelo magistrado, que reconhecerá sua ilicitude e determinará o consequente desentranhamento dos autos (EBERHARDT, 2015, p. 15).

Nesse sentido, lecionam Lopes Junior e Morais da Rosa (2016):

a proibição de valoração probatória com a consequente exclusão física dela e de toda a derivada. É a 'pena de inutilizzabilità' consagrada pelo direito italiano. Mas é importante que não se confunda a 'teoria das nulidades' com a teoria da prova ilícita, ainda que ambas se situem o campo da ilicitude processual, guardam identidades genéticas distintas. É por isso que não se aplicam às provas ilícitas as teorias da preclusão ou do prejuízo. Esse é um diferencial crucial, não raras vezes esquecido

A Constituição Federal prevê em seu artigo $5^{\circ}$, inc. LVI, a inadmissibilidade das provas obtidas por meios ilícitos, ao dispor que: "são inadmissíveis, no processo, as provas obtidas por meios ilícitos; o Código de Processo Penal reproduz tal dispositivo constitucional ao consagrar o mesmo princípio em seu artigo 157, caput, que dispõe: "São inadmissíveis, devendo ser desentranhadas do processo, as provas ilícitas, assim entendidas as obtidas em violação a normas constitucionais ou legais". Portanto, ainda que não haja previsão normativa acerca das consequências jurídicas sobre a quebra da cadeia de prova, tal conduta tolhe dispositivo expresso de lei processual penal e da própria Carta Magna, e, sob tal ótica, a prova deverá ser considerada, pelo juiz competente, como inválida, ou seja, imprestável ao processo penal. Admitir interpretação diversa, além de ferir os princípios do contraditório judicial e da ampla defesa, leva a norma à plataforma do descrédito.

Considerando, destarte, que a quebra da cadeia de custódia é causa de invalidade das provas, resta saber se tal invalidade mergulha no campo das provas ilícitas ou ilegítimas. Provas ilícitas são aquelas em o agente, para sua produção, viola norma de direito material (penal); provas ilegítimas são aquelas em que o agente, para sua produção, viola norma processual penal. O melhor entendimento deve apoiar-se em considerá-las como provas ilegítimas, já que a quebra representa efetiva violação de um ou mais dispositivos processuais penais, ou seja, dos artigos 158-A ao 158-F. Tal reconhecimento, pelo juiz, implicará em declarar a nulidade da prova pericial, na forma do art. 564, inc. IV, do Código de Processo Penal e, por consequência, das provas subsequentes a ela produzidas, desde que sua existência guarde relação umbilical com a prova ilegítima, já que, neste caso, serão consideradas ilegítimas por derivação.

Não se pode olvidar, porém, que se a quebra da cadeia de custódia foi dolosa a prova poderá ser considerada ilícita, pois neste caso o agente, possivelmente, viola norma penal para sua produção, ou seja, macula o art. 347, do Código Penal (fraude processual); fato que implicará, também, sanções administrativas.

Em resumo, o direito à prova consiste em um desdobramento de garantias constitucionais, não se tratando de um direito ilimitado. Para tanto, a busca para que se evitem vícios na produção probatória deve ser incansável, tendo em vista que sua ocorrência acarretará a invalidade da prova, podendo ter como consequência uma nulidade processual ou uma sanção da inadmissibilidade do elemento probatório, a depender do caso. Essa discussão é importante considerando que, conforme a doutrina majoritária, a prova ilegítima é absolutamente inadmissível no processo, e, por extensão, aquela derivada dela, salvo quando houve quebra do nexo de causalidade entre ela (derivada) e a prova originariamente ilícita, o que pode ocorrer, por exemplo, nos casos de uma fonte independente ou de uma descoberta inevitável.

\section{Conclusão}

A cadeia de custódia pode ser conceituada como o conjunto de procedimentos adotados desde o reconhecimento do vestígio, no cenário fático-criminal, até a futura avaliação pericial e, por consequência, seu descarte. $\mathrm{O}$ instituto assegura a mesmidade e a confiabilidade da prova penal, por meio da manutenção correta do material colhido, bem como sua adequada identificação e registro da trajetória percorrida, assim, permitindo a rastreabilidade, a autenticidade e a licitude da prova.

Destaca-se a significativa contribuição da Lei 13.964/2019, que introduziu, no ordenamento jurídico brasileiro, o instituto da cadeia de custódia, por meio da inclusão, no Código de Processo Penal, dos artigos 158-A ao 158-F, os quais normatizam regras para assegurar a integridade da prova pericial.

No que concerne à ruptura da cadeia de custódia, a Lei $\mathrm{n}^{\circ}$ 13.964/2019 não estabeleceu quais seriam as consequências jurídicas sobre a quebra da cadeia, ou seja, se seriam válidas ou não as provas produzidas à revelia das disposições que cercam a matéria. Portanto, dada a ausência de dispositivo concreto, pugna-se que, sob a lente do processo penal democrático, que tem compulsoriedade de atentar às garantias constitucionais, notadamente aquelas ligadas a ampla defesa, ao contraditório 
e ao devido processo legal, que seja reconhecida sua invalidade. Por essa razão, toda e qualquer prova pericial, produzida à revelia da cadeia de custódia, deve ser declarada, pelo julgador, ilegítima por violar norma processual e, por isso, desentranhada do processo, assim como aquelas que dela derivaram em conexão, sem prejuízo das responsabilidades penal e administrativa contra o servidor que tenha quebrado a cadeia de custódia.

\section{Referências}

BADARÓ, G.H. A cadeia de custódia e sua relevância para a prova penal. In: SIDI, R.; LOPES, A.B. Temas atuais da investigação preliminar no processo penal. Belo Horizonte: D’Plácido, 2018.

BORRI, L.A.; SOARES JUNIOR, R. A cadeia de custódia no Pacote Anticrime. Boletim IBCCRIM , n.335, 2020.

DALLAGNOL, D.M.; CÂMARA, J.A.S.R. A cadeia de custódia da prova. In: SALGADO, D.R.; QUEIROZ, R.P. A prova no enfrentamento à macrocriminalidade. Salvador: Juspodivm, 2016.

EBERHARDT, M. O STJ e apreservação da cadeia de custódia da prova. 2015. Disponível em: $<$ https:// canalcienciascriminais. com.br/o-stj-e-a-preservacao-da-cadeia-de-custodia-da-prova/>. Acesso em: 3 jan. 2021.

FERNANDES, A.S.; GRINOVER, A.P.; GOMES FILHO, A.M. As nulidades no processo penal. São Paulo: Revista dos Tribunais, 2011.
GIOVANELLI, A..; GARRIDO, R.G. A perícia criminal no Brasil como instância legitimadora de práticas policiais inquisitoriais. Rev. Labor. Estud. Violência UNESP, n.7, p.1983-2192, 2011.

GRINOVER, A.P. Liberdades públicas e processo penal. São Paulo: Revista dos Tribunais, 1982.

LIMA, R.B. Manual de Processo Penal. Salvador: Juspodvim, 2020 .

LOPES JUNIOR, A. Direito Processual Penal. São Paulo, Saraiva, 2020.

MATIDA, J. A cadeia de custódia é condição necessária para a redução dos riscos de condenações de inocentes. Boletim IBCCRIM, n.331, 2020. Disponível em: https://ibccrim.org.br/ publicacoes/edicoes/51/441. Acesso em: 21 set. 2020.

ROSA, A.M.; LOPES JUNIOR, A. A importância da cadeia de custódia para preservar a prova penal. 2016. Disponível em <https://www.conjur.com.br/2015-jan-16/limite-penalimportancia-cadeia-custodia-prova-penal $>$. Acesso em: $11 \mathrm{dez}$. 2020.

BRASIL. Ministério da Justiça. Secretaria Nacional de Segurança Pública. Diagnóstico da perícia criminal no Brasil. Brasília: Secretaria Nacional de Segurança Pública, 2013.

PRADO, G. Ainda sobre a quebra da cadeia de custódia das provas. Boletim do IBCCrim, n.262, 2014a.

PRADO, G. Prova penal e sistema de controles epistêmicos: a quebra da cadeia de custódia das provas obtidas por métodos ocultos. São Paulo: Marcial Pons, 2014b. 